\title{
Meckel's Diverticulum with Multiple Ileal Ulcers as a Source of Massive Gastrointestinal Haemorrhage in a Three Year Old Child
}

\author{
Hamid $\mathbf{R}^{1}$, Wani $\mathrm{SA}^{2}$, Shera $\mathrm{AH}^{3}$, Khurshid $\mathrm{S}^{4}$, Bhat $\mathrm{NA}^{5}$, Baba $\mathrm{AA}^{6}$ \\ ${ }^{1}$ Dr. Raashid Hamid, MBBS, MS, Senior Resident, \\ ${ }^{2}$ Dr. Sajad A Wani MBBS, MS. Senior Resident, ${ }^{3}$ Dr.A \\ $\mathrm{H}$ Shera, MBBS, MS, Mch Professor, ${ }^{4} \mathrm{Dr}$. Sheikh \\ Khurshid, MBBS, MS. Professor, ${ }^{5}$ Dr. NA Bhat, MBBS. \\ MS. Mch Asst. Prof. ${ }^{6}$ Dr. Aejaz A Baba, MBBS, MS, \\ Mch Asst. Prof. All from the Department of Paediatric \\ Surgery, SKIMS, Srinagar, India.
}

\section{Introduction}

ohann Friedrich Meckel in 1809 first described MD. Meckel's diverticulum is a common anomaly of small intestines that results due to failure of the omphalomesenteric duct to obliterate. Incidence of MD ranges from 1.2 to $1.7 \%$, with a male female ratio of $3: 2^{1,2}$.

The complications of MD include inflammation, perforation, haemorrhage, intussusception, volvulus, intestinal obstruction and malignant transformation ${ }^{3}$. Majority of the symptomatic diverticulum present during paediatric age group. Life time complication rate has been reported to be around $4 \%{ }^{4}$. Computed Tomography and Ultrasonography (USG) are usually of little value. ${ }^{99 \mathrm{~m}} \mathrm{Tc}$ pertechnetate gives an accurate diagnosis when uptake occurs in ectopic gastric mucosa ${ }^{5}$. Diagnosis is confirmed by diagnostic laparotomy. We present a 3 year old male child with massive episodic gastrointestinal bleed who was subjected to ${ }^{99 m}$ Tc-pertechnetate scan, the study was positive and subsequently patient was explored, which confirmed the diagnosis of a bleeding Meckel's diverticulum.

\section{The Case}

A 3-year old male toddler was referred from medical paediatric department to our surgical department with 6 days history of episodic lower gastrointestinal bleeding having hemoglobin of $3 \mathrm{gm} / \mathrm{dl}$. History narrated by the parents revealed that their baby had 3 to 5 episodes of

\section{Address for correspondence \\ Dr. Raashid Hamid \\ E-mail: drraashidhamid@gmail.com}

This work is licensed under a Creative Commons Attribution 3.0 License.

\begin{abstract}
Meckel's Diverticulum (MD) is a frequent congenital anomaly of small bowel often difficult to diagnose. It is usually asymptomatic and can present as bleeding, obstruction and inflammation. We report a case of MD in a 3 year old male child, diagnosed by ${ }^{99 \mathrm{~m} T c}$ pertechnetate scan and confirmed on laparotomy. Excised specimen revealed a large MD with multiple ileal ulcers, as a source of massive bleeding per rectum. The clinical features and need for early diagnosis and treatment are discussed.
\end{abstract}

Key words: Meckel's diverticulum, Bleeding per rectum, Multiple ileal ulcers.

bleeding per rectum per day, dark black in color. Each episode was around 30 to $40 \mathrm{gm}$ in quantity. Bleeding was associated with crampy abdominal pain. There was no history of vomiting, fever, or dysuria. During these six days USG, colonoscopy and dye study of intestines were normal.

The patient's $\mathrm{Hb}$ was $3 \mathrm{~g} / \mathrm{dl}$, a total leucocyte count of 13000 with a predominance of granulocytes (74\%) and a normal platelet count. The coagulation studies revealed PTI of 95\% INR;1.4 and Aptt;16 sec, chest and abdominal radiographs were unremarkable. USG abdomen and colonoscopy were also normal. After admission, patient was referred to our Paediatric Surgery Department we subjected the baby to thorough physical examination. Positive findings included gross Pallor, mild diffuse abdominal tenderness. Digital rectal examination confirmed the stool color which was dark black as was described by the parents. There was no other local lesion in peri-anal area or rectum. ${ }^{99 \mathrm{~m} T c-}$ pertechnetate scan done, which showed radionuclide activity in right iliac fossa. [Figure 1]

How to cite this article?

Hamid R, Wani Sajad, Shera AH, Sheikh Khurshid, Bhat NA, Baba AA. Meckel's Diverticulum with Multiple lleal Ulcers as a Source of Massive Gastrointestinal Haemorrhage in a Three Year Old Child. J Nepal Paediatr Soc 2013;33(3):227-229. 


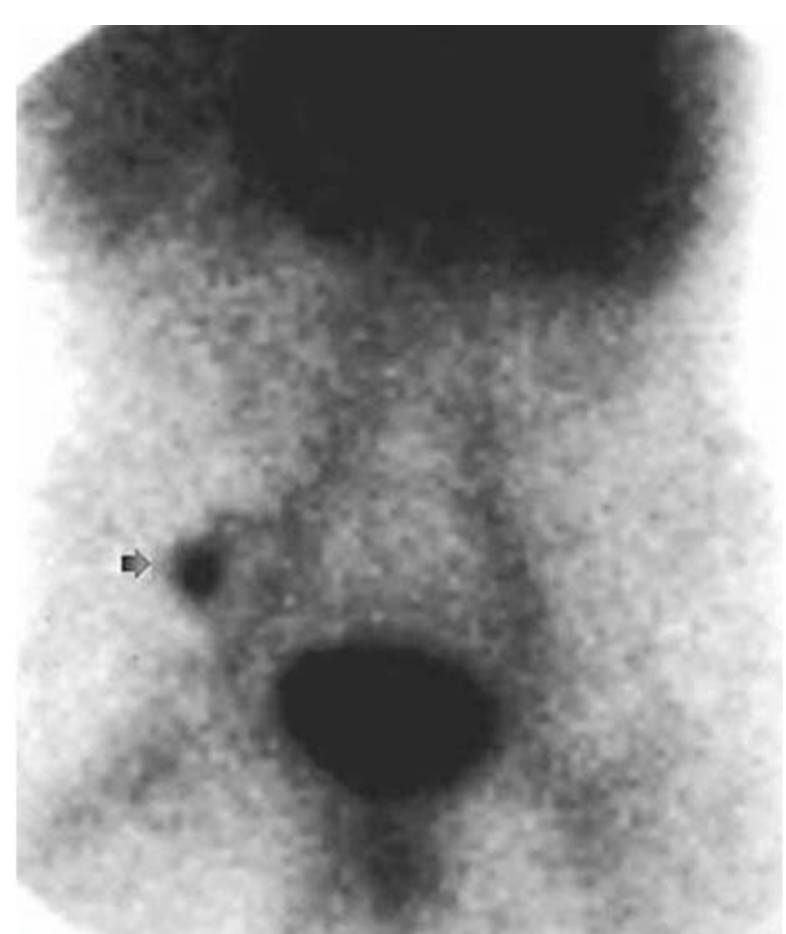

Fig 1: ${ }^{99 m}$ Tc-pertechnetate scan with radionuclide activity in right iliac fossa.

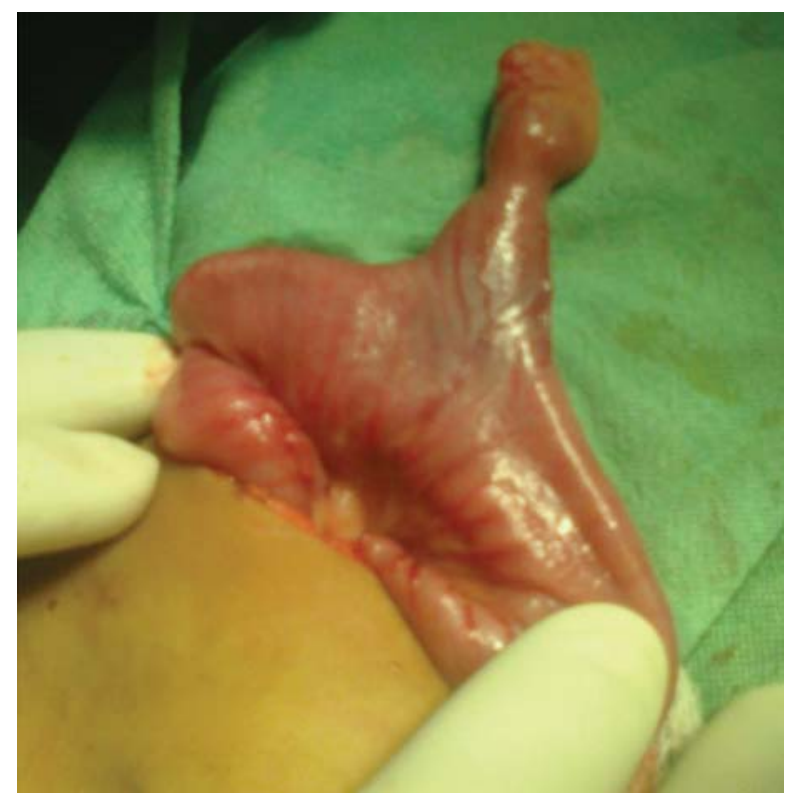

Fig 2: Itraoperative photograph of Meckel's Diverticulum

Baby was explored in emergency operation theatre. A $3.5 \mathrm{~cm}$ long Meckel's diverticulum was found just $32 \mathrm{~cm}$ from ileocecal valve. The diverticulum was broad based. Resection of the ileum was done $5 \mathrm{~cm}$ proximal and $4 \mathrm{~cm}$ distal to the diverticulum (Figure 2). The specimen was opened along the antimesenteric boarder which revealed multiple ileal ulcers (Figure 3). Anastomosis was done between the two ends of ileum. Baby did well postoperatively. Histopathology revealed ectopic gastric mucosa in the diverticulum and multiple peptic ulcers in the resected specimen.

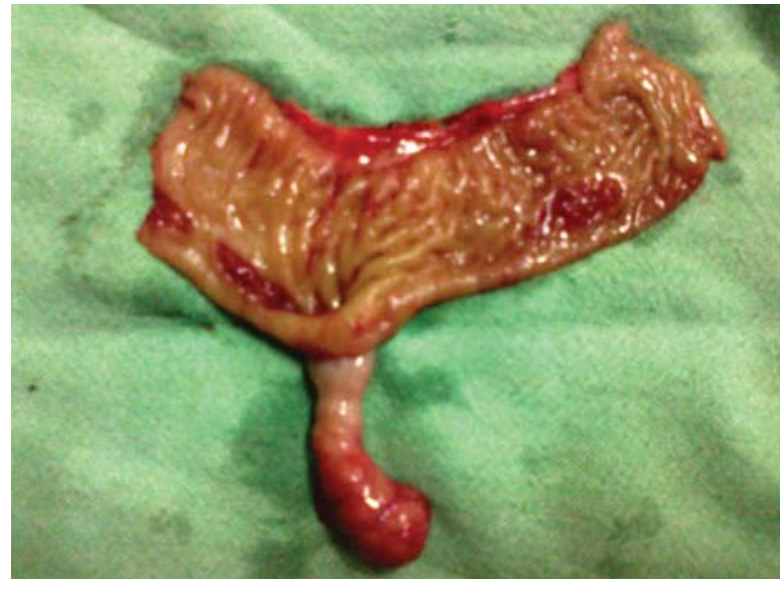

Fig 3: Ileal lumen containing Multiple ileal ulcers.

\section{Discussion}

Clinical symptoms arise from complications MD carriers have a $4 \%$ life time risk of developing a complication ${ }^{1,6}$. Haemorrhage results due to ileal mucosal ulceration next to an acid-producing gastric mucosal tissue. Clinical presentation varies from recurrent minimal intestinal bleeding to a massive shock-producing hemorrhage which is usually painless. Other clinical manifestations include perforation, intussuception, diverticulitis, Littre's hernia. Tumors are reported in $0.5-3 \%$ symptomatic diverticula in adulthood ${ }^{7}$.

Preoperative diagnosis can be challenging and often difficult to establish. Complicated MD has a spectrum of radiological features but are not always diagnostic. In diagnosing the bleed from Meckel's diverticulum, the upper and lower gastrointestinal endoscopy play no role as they are not able to visualize the ileal lumen. It is very difficult to distinguish an ileal loop from Meckel's diverticulum on ultrasonography and CT. As mentioned our case USG, Upper GI and lower $\mathrm{GI}$ endoscopy were normal and these could not help in arriving at diagnosis. Radionuclide ${ }^{99 \mathrm{~m} T c-p e r t e c h n e t a t e}$ isotope scan may diagnose MD when uptake occurs in ectopic gastric mucosa or by identifying the site of gastrointestinal bleeding. Accuracy reported is around $90 \%$ in paediatric patients ${ }^{8}$ and drops to only $46 \%$ in adult group ${ }^{9}$. In our case, the ${ }^{99 m}$ Tc-pertechnetate scan was positive after delayed imaging showing radioactivity in right iliac fossa. The correct diagnosis is finally confirmed on laparotomy as in our case. The laparotomy affords the possibility of simultaneous surgical resection which is definitive cure of symptomatic MD. Length and width of the diverticulum are also felt to be determinant in symptomology. Mackey et al found that symptomatic diveticula were more likely to be $2 \mathrm{~cm}$ or greater in length ${ }^{2}$. Broad based diverticula were less likely to be symptomatic because of lower risk of obstruction. As demonstrated in our case, the length of the Mackel's 
diverticulum was $3.5 \mathrm{~cm}$ and was symptomatic. Hence inferring that long diverticulum may have more chances of bleeding. There is general agreement that symptomatic MD should be resected by either open or laparoscopic procedures.

As our patient presented with bleeding and Meckel's scan was positive after all other investigations were negative. The MD in our case had lead to multiple peptic ulceration of the ileum as shown in the specimen photograph. The probable cause of the massive GI bleed in our case was multiple ileal ulcers which is very rare. The cause of multiple ulcers could be due the delay in diagnosis.

There should not be any delay in having a suspicion of MD as a cause of GI bleed and the patient should undergo a ${ }^{99 m}$ Tc-pertechnetate scan and subsequent laparotomy. These patients should be referred immediately to centres having ${ }^{99 \mathrm{~m}} \mathrm{Tc}$-pertechnetate scan facility and trained paediatric surgeon which can alter the course of the disease that can sometimes be fatal.

\section{Conclusion}

Proper history, clinical examination and early diagnosis and treatment can be life saving. Exploratory laparotomy decreases the time spent for diagnosis and theoretically avoids the morbidity and mortality of delayed diagnosis.

\section{References}

1. Daniela Codrich, Andrea Taddio, Jurgen Schleef, Allessandro Ventura, and Federico Marchetti. Meckel's diverticulum masked by a long period of intermittent recurrent subocclusive episodes. World J Gastroenterol 2009;15:2809-11.
2. Mackey WC, Dineen P. A fifty-year experience with Meckel's diverticulum. Surg Gynecol Obstet 1983;156:54-6.

3. Anderson DJ. Carcinoid tumor in Meckel's diverticulum: laparoscopic treatment and review of the literature. JAm Osteopath Assoc 2000;100:43234

4. Soltero MJ, Bill AH. The natural history of Meckel's diverticulum and its relation to incidental removal. A study of 202 cases of diseased Meckel's diverticulum found in King County Washington, over a fifteen year period. Am J Surg 1976;132:168-73.

5. Yinlu Ding, Yong Zhou, Zhipeng Ji, Jianliang Zhang, and Qisan Wang Laparoscopic Management of Perforated Meckel's Diverticulum in Adults. Int J Med Sci 2012;9(3):243-47.

6. Martin JP, Connor PD, Charles K. Meckel's diverticulum. Am Fam Physician 2000;61:10371042, 1044

7. Yamaguchi M, Takeuchi S, Awazu S. Meckel's diverticulum investigation of 600 patients in the Japanese literature. Am J Surg 1978;136:247-49

8. Cooney DR, Duszynski DO, Camboa E. et al. The abdominal technetium scan (a decade of experience) J Pediatr Surg 1982;17:611-19

9. Schwartz MJ, Lewis JH. Meckel's diverticulum: pitfalls in scintigraphic detection in the adult. $A m \mathrm{~J}$ Gastroenterol 1984;79:611-18. 